\title{
Information System of Performance Assesment on Startup Business using Simple Multi-Attribute Rating Technique Exploiting Ranks (SMARTER)
}

\author{
Alen Adriyanti Tangkesalu ${ }^{1, *}$, Jatmiko Endro Suseno ${ }^{2}$ \\ ${ }^{1}$ Magister Program of Information System, School of Postgraduate Studies, Diponegoro University, Semarang - \\ Indonesia \\ ${ }^{2}$ Department of Physic, Faculty of Sains and Mathematic, Diponegoro University, Semarang - Indonesia
}

\begin{abstract}
Performance evaluation system has a very strategic role in improving the performance of a company. Companies generally judge performance based only on the financial aspect only, regardless of other aspects that are also not less important. This study aims to build a performance evaluation system using a Balanced Scorecard perspective framework that is a financial perspective, customer perspective, internal business process perspective and learning and growth perspective, which can assist decision makers in evaluating performance and prioritizing competitive alternative measures in enhancing the achievement of strategic objectives company. Implementation of the Simple MultiAttribute Rating Technique Exploiting Ranks (SMARTER) method of performance evaluation system provides the right performance evaluation data. The data were obtained by calculating the criteria and sub-criteria weightings from 4 perspectives and 14 key performance indicators (KPIs) based on the BSC perspective using Rank Order Centroid (ROC) weighting to obtain criteria and sub-criteria rating according to importance level. Base on case studies, the results of this research indicate that the perspective of internal business processes with a priority weight of 0.521 is the most important perspective in evaluating business startup performance, then the customer perspective with a weight of 0.271 , then learning and growth perspective with a weight of 0.146 and perspective finance with a weight of 0.063 . While the asset turnover performance indicator with a weight value of 0.009 and profit investment with a weight of 0.004 from a financial perspective are important factors for improvement.
\end{abstract}

Keywords: Balanced Scorecard; Simple Multi-Attribute Rating Technique Exploiting Ranks; Rank Order Centroid.

\section{Introduction}

The Startup is an institution created to create new and innovative products or services under high uncertainty [1] and is a business initiative with high growth potential for long-term business for investors [2]. But the startup business presence has different difficulty levels compared to other businesses. Not a few startup businesses that fail. One of the things that can not be separated from startup business is a risk. Lack of experience can be used as a reference that will pose risks during startup operations. The risks facing startup are technical (product), a customer (market), and business model. This is closely related to the performance of the business startup. To find out how the performance of a business startup and its development in the future, it is necessary to have a performance appraisal system.
The enterprise performance is the perception from all of the company resources during a certain period of times which affected by company's operational activity in order to utilize its resources [3]. Competitive advantage is the basis of a successful long-term business operation for a company and is related to the performance of the company itself. The competitive advantage of achieving a certain level of business performance is a key prerequisite for a successful operation of a company in the long term [4]. The company's performance will generate profits, increase production process efficiency and its effectiveness in turning input factors into final products [5]. In general, the company's performance is reflected in better corporate stability and ability to adapt to change and find solutions to such changes.

* Corresponding author: adriyanti1004@gmail.com 
The weakness of the performance measurement at the company is generally only focused on the financial sector only [6], whereas to improve the competitiveness of firms, the measurement of financial performance alone is not enough because it only sees the performance from a financial standpoint and ignores other points of view that are equally important. The purpose of the performance measurement system is to assist in establishing the company's.

Some frameworks such as balanced scorecards assisting the design and the implementation of the performance measurement systems already have been identified [7], performance prism [8], performance measurement matrices [9] and the result and the determinant framework [10] and the most notable of which is the balanced scorecard. This multidimensional framework is used to balance financial and non-financial measures [11-12]. The existence of a strategy map showing interconnected objective strategies with Key Performance Indicators (KPIs) in each perspective makes it easy for managers to monitor how much success and failure the company's chosen strategy [12].

The Simple Multi-Attribute Rating Technique Exploiting Rank (SMARTER) method is a development of the SMART (Simple Multi-Attribute Rating Technique) method. The decision-making technique for multi-criteria SMARTER is in accordance with the theory of that each alternative consisting amount of valuable criteria and its describes the comparison between a criterion with other criteria. ROC is based on the importance or priority of the criteria. The ROC technique assigns weight to each criterion according to the rank that is judged by its priority level [13].

This research aims to build a scoring system to analyze performance using the Simple Multi-Attribute Rating Technique Exploiting Rank (SMARTER) method based on the Balance Scorecard perspective framework, which can assist decision makers in evaluating performance and prioritizing competitive alternative steps in enhancing the achievement of corporate strategic goals..

\section{Literature Review}

\subsection{The Concept of a Balanced Scorecard}

The Balanced Scorecard is used for measuring the performance with due regard to the balance between the financial and non-financial side, between short and longterm and involving internal and external factors [6]. Balance Scorecard as a performance measurement system can be used as a tool to control, analyze and revise the organization's strategy. To measure future performance, comprehensive measurement is needed that includes four perspectives: financial, customer, internal business processes, and learning and growth. Based on the concept of financial performance Balance Scorecard is the result or result of non-financial performance (customer, internal business process, and learning and growth) [12].

In the strategic management system there are two important stages, namely the planning and implementation phase, if the vision and strategy can be expressed in the form of strategic objectives, clear size and target, then communicated to every member of the organization, it is expected that each member of the organization can understand and apply it vision organizational strategy is achieved.

Before the Balanced Scorecard is implemented, the organization first prepares the 5 stages of the BSC to develop business strategies, develop organizational goals, develop strategic maps for organizational business strategies, assess performance and develop initiatives [14].

\subsection{Metode SMARTER}

The Simple Multi-Attribute Rating Technique Exploiting Ranks (SMARTER) method is the development of the SMART (Simple Multi-Attribute Rating Technique) method. The SMARTER method is a multi-criteria decision-making method. Weighing the criteria on the method depends on the order of priority attributes considered most important by using Rank Order Centroid (ROC) determination techniques.

This SMARTER multi-criteria decision-making technique is based on the theory that each alternative consists of a number of criteria that have value and each criterion have a weight that describes how important it is compared to other criteria. Weighting in the SMARTER method uses ranges between 0 and 1, making it easier to calculate and value comparisons in each alternative [15-16]. ROC is based on importance or priority criteria. The ROC technique assigns weight to each criterion according to the rank assessed by the priority level [17].

The basic idea can be illustrated by 2 attributes $A$ and B. If A ranks first, then the weights should be between 0.5 and 1 so that the midpoint of the interval of 0.75 is taken as the approximate weight, which is the basis of the minimum commitment principle. Because the weight of $B$ will be 0.25 (is the midpoint between 0 and 0.5 ). Usually formed with the statement "criterion 1 is more important than criterion 2, which is more important than criterion 3" and so on until the " $n$ " criterion, written $\mathrm{Cr}_{1} \geq \mathrm{Cr}_{2} \geq \mathrm{Cr}_{3} \geq \ldots \geq \mathrm{Crn}$. and to determine its weight, given the same rule of $W_{1} \geq W_{2} \geq W_{3} \geq \ldots \geq W n$ where $W_{1}$ is the weight for $\mathrm{C}_{1}$.

The steps in the SMARTER method design are:

a. Identify the problem.

b. Define criteria and subcriteria..

c. Rating for each criteria and subcriteria..

d. Calculate the criteria and subcriteria weight using ROC weights.

If $\mathrm{Cr}_{1} \geq \mathrm{Cr}_{2} \geq \mathrm{Cr}_{3} \geq \ldots \geq \mathrm{Crk}$, then $\mathrm{W}_{1} \geq \mathrm{W}_{2} \geq \mathrm{W}_{3} \geq \ldots \geq$ Wk. Or can be explained as follows:

$\mathrm{W}_{1}=(1+1 / 2+1 / 3+\ldots+1 / \mathrm{K}) / \mathrm{K}$

$\mathrm{W}_{2}=(0+1 / 2+1 / 3+\ldots+1 / \mathrm{K}) / \mathrm{K}$

$\mathrm{W}_{3}=(0+0+1 / 3+\ldots+1 / \mathrm{K}) / \mathrm{K}$

$\mathrm{W}_{\mathrm{K}}=(0+\ldots+0+1 / \mathrm{K}) / \mathrm{K}$

where $\mathrm{K}$ expressed as the number of criteria. In general ROC weighting can be formulated in Equation (1) [15-16]:

$$
W_{k}=\frac{1}{\mathrm{~K}} \mathbf{\Sigma}_{\mathrm{i}=\mathrm{k}}^{\mathrm{K}}\left(\frac{1}{\mathrm{i}}\right)
$$


where $W_{k}$ is the Value of Weight criteria $k, K$ as many criteria, and " $\mathrm{i}$ " is an alternative value.

e. Calculate the final weight of each criterion

The final weight $\left(\mathrm{U}_{\mathrm{h}}\right)$ obtained from the multiplication of the $\mathrm{k}$ criteria weight $\left(\mathrm{W}_{\mathrm{k}}\right)$ with the utility value of $k$ criteria for the $h$ alternative $\left(\mathrm{U}_{\mathrm{h}}\left(\mathrm{X}_{\mathrm{hk}}\right)\right)$. The utility value is the sum of the multiplication of each sub-criteria by the weight of the criterion. The result of the final weighting can be used to assess the company and determine which performance needs to be improved based on the KPI from each Balance Scorecard perspective. The final weighting calculation can be formulated in Equation (2) $[15-16]$.

$$
U_{\mathrm{h}}=\sum_{\mathrm{k}=1}^{\mathrm{K}} \mathrm{W}_{\mathrm{k}} \mathrm{U}_{\mathrm{h}}\left(\mathrm{X}_{\mathrm{hk}}\right)
$$

\section{Research methods}

The data used in this research are the data collected by interviewing and handing questioner to the company, in order to find of company profiles, vision, mission, strategy, and also financial report, customer relation, internal business process. Questionnaires were distributed to the customer and management of the business startup.

This research is done with several stages, with the aim to get maximum result, a stage which will be done that is planning, data collection, and processing and data analysis. In the planning stage, the design of Balanced Scorecard framework is applied, besides that SMARTER method is also needed to weight each criterion from Balance Scorecard in order to obtain the priority of performance criteria that must be improved. System development using PHP and MySQL programming.

The process of collecting data uses Balance Scorecard literature on performance evaluation at company and result of the interview process with management regarding performance evaluation. By formulating the results according to the perspective such as financial, customer, internal's business process, and also learning and growth.. The results of questionnaires are used for the process of calculating the weight of each perspective and performance indicators using ROC weighting and then done the ranking process to get performance priority using Simple Multi-Attribute Rating Technique Exploiting Rank (SMARTER). Questionnaires were distributed to management and employees and customers at the startup of the business to conduct the assessment. While the process of data processing is done following the stages in the method of Simple Multi-Attribute Rating Technique Exploiting Ranks, that is by identifying criteria and subcriteria, which in the framework of balance scorecard criteria expressed as perspective and subcriteria expressed as performance indicators.

The next process is to rank every perspective and performance indicator, where the data obtained from the filling questionnaires by the management, employees and customers to conduct the assessment by expressing the relative importance of the criteria and subcriteria.

\section{Results and Discussion}

\subsection{Result}

This research uses a multilevel (Likert scale) questionnaire on each answer provided, to determine the priority level of each perspective and performance indicator. The perspective of the Balanced Scorecard framework and its performance indicators are respectively:

a. Internal Business Process Perspective (K01) has performance indicators: innovation (SK011), postsale service (SK012), and operation (SK013).

b. Customer Perspective (K02) has performance indicators: customer satisfaction (SK021), quality of service (SK022), and market share (SK023).

c. Learning and Growth Perspective (K03) has performance indicators: human resource development (SK031), employee satisfaction (SK032), and Employee loyalty (SK033).

d. Financial Perspective (K04) has performance indicators: total transactions (SK041), profit margin (SK042), asset turnover (SK043), and profit investment (SK044).).

The priority level from the perspective and the highest performance scorecard performance indicator is internal business process perspective with weighted value 4,133 , the customer perspective with 4,124 weight value, then learning and growth perspective with weight value 3,947 and the last is financial perspective with weight value 3,713 .

The results show that internal business processes are more a priority from a customer perspective, learning and growth perspective and financial perspective, as shown in Table 1.

Table 1. Priority Level Perspective and Performance Indicators

\begin{tabular}{|c|c|c|c|}
\hline \multirow{3}{*}{ Criteria } & Subcriteria & $\begin{array}{c}\text { Results of } \\
\text { subcriteria } \\
\text { weighting }\end{array}$ & $\begin{array}{c}\text { Subcriteria } \\
\text { Rating }\end{array}$ \\
\hline \multirow{3}{*}{ K01 } & SK011 & 4.400 & 1 \\
\cline { 2 - 4 } & SK012 & 4.067 & 2 \\
\cline { 2 - 4 } & SK013 & 3.933 & 3 \\
\hline \multirow{4}{*}{ K02 } & SK021 & 4.297 & 1 \\
\cline { 2 - 4 } & SK022 & 4.086 & 2 \\
\cline { 2 - 4 } & SK023 & 4.059 & 3 \\
\cline { 2 - 4 } & SK024 & 4.054 & 4 \\
\hline \multirow{3}{*}{ K03 } & SK031 & 4.200 & 1 \\
\cline { 2 - 4 } & SK032 & 3.840 & 2 \\
\cline { 2 - 4 } & SK033 & 3.800 & 3 \\
\hline \multirow{3}{*}{ K04 } & SK041 & 4.000 & 1 \\
\cline { 2 - 4 } & SK042 & 3.950 & 2 \\
\cline { 2 - 4 } & SK043 & 3.900 & 3 \\
\cline { 2 - 4 } & SK044 & 3.000 & 4 \\
\hline
\end{tabular}

Calculations by the SMARTER method are used in determining the priority of ROC weighting criteria and subcriteria. The criteria and subcriteria used in this study are based on the Balance Scorecard perspective 
framework. The calculation of the criteria and subcriteria weighting of the SMARTER method uses ROC weighting, which is based on the importance of each criterion and subcriteria ie: if $\mathrm{Cr}_{1} \geq \mathrm{Cr}_{2} \geq \mathrm{Cr}_{3} \geq \ldots \geq \mathrm{Cr}_{\mathrm{k}}$, then $\mathrm{W}_{1} \geq \mathrm{W}_{2} \geq \mathrm{W}_{3} \geq \ldots \geq \mathrm{Wk}$.., where $\mathrm{K}$ expressed as the number of criteria and $i$ as an alternative value as in Equation (1). The next step is a multiplication of ROC weight criteria with ROC subcriteria weight to get the final weight, as in Equation (2). The result of ROC weighting criteria and subcriteria and final weights is shown in Table 2.

Table 2. Results Calculation of ROC Weight Criteria and Subcriteria and Final Weight

\begin{tabular}{|c|c|c|c|c|}
\hline \multirow{2}{*}{ Criteria } & $\begin{array}{c}\text { Weight } \\
\text { of ROC } \\
\text { criteria }\end{array}$ & Subcriteria & $\begin{array}{c}\text { Weight of } \\
\text { ROC } \\
\text { subcriteria }\end{array}$ & $\begin{array}{c}\text { The } \\
\text { final } \\
\text { weights }\end{array}$ \\
\hline \multirow{3}{*}{ K01 } & \multirow{3}{*}{0.521} & SK011 & 0.611 & 0.318 \\
\cline { 3 - 5 } & & SK012 & 0.278 & 0.145 \\
\cline { 3 - 5 } & & SK013 & 0.111 & 0.058 \\
\hline \multirow{3}{*}{ K02 } & \multirow{3}{*}{0.271} & SK021 & 0.521 & 0.141 \\
\cline { 3 - 5 } & & SK022 & 0.271 & 0.073 \\
\cline { 3 - 5 } K03 & \multirow{3}{*}{0.146} & SK023 & 0.146 & 0.039 \\
\cline { 3 - 5 } & & SK024 & 0.063 & 0.017 \\
\cline { 3 - 5 } & & SK031 & 0.611 & 0.089 \\
\hline \multirow{3}{*}{ K04 } & \multirow{3}{*}{0.063} & SK032 & 0.278 & 0.041 \\
\cline { 3 - 5 } & & SK041 & 0.111 & 0.016 \\
\cline { 3 - 5 } & & SK042 & 0.521 & 0.033 \\
\cline { 3 - 5 } & & SK043 & 0.146 & 0.009 \\
\hline & & SK044 & 0.063 & 0.004 \\
\hline
\end{tabular}

\subsection{Discussion}

The result that has been achieved by using performance assessment system at business startup shows that internal business process (K01) with priority weight of 0.521 is the most important perspective in business startup performance evaluation with $52 \%$, customer perspective (K02) with weight 0.271 with total $27 \%$, then learning and growth perspective (K03) with weight of 0.146 with $14 \%$ and financial perspective (K04) with weight of 0.063 to $6 \%$.

According to these results which gain, it can be seen that the system of business startup performance assessment more emphasis on business achievement of internal business processes. Although financial and customer perspectives are most emphasized by management but in this research, the financial perspective is at a very low level among other perspectives on business startup.

For strategic goals of innovation (SK011) with a priority weight of 0.318 is the most important strategic goal. Post-sales service (SK012) is the second strategic target with the weight of 0.145 , customer satisfaction (SK021) occupies the third position with the weight of 0.141 , the target of the human resources development (SK031) in the fourth position with the weight of 0.089 . Then the quality of service (SK022) is the fifth strategic target with the weight of 0.073 , and then to the strategic target with the smallest priority weights in sequence ie operation (SK013) with weight of 0.058 , employee satisfaction (SK032) with weight of 0.041, market share (SK023) (SK024) with weight of 0.017, employee loyalty (SK033) with weight of 0.016 , asset turnover (SK043) with weight of 0.009 and the smallest is profit investment (SK044) with priority weight of 0.004 .

From the results of performance appraisal system, shows that the indicator of asset turnover performance with a weight value of 0.009 and profit investment with a weight value of 0.004 from a financial perspective is an important factor that most emphasized by the business startup to do improvement.

\section{Conclusion}

Performance appraisal system at a business startup uses 4 perspective balance scorecard with 14 performance indicators or key performance indicator (KPI) as the achievement of corporate strategic goals.

From the research, result using performance appraisal system, achievement from the combination of Balance Scorecard frame and Simple Multi-Attribute Rating Technique Exploiting Ranks method can be applied to the business startup evaluation process because with this method obtained the highest performance result from internal business process perspective and customer. On the internal business process perspective the highest performance indicators are innovation and post-sales service, while on the customer perspective, the highest performance indicator is customer satisfaction.

\section{Reference}

1. E. Ries, Lean Startup: How Today's Entrepreneurs Use Continous Innovation to Create Radically Successful Business (Crown Business, New York, 2011)

2. H. Janakova, Procedia Economics and Finance 34, $73-80$ (2015)

3. E.A. Helfert, D.B.A., Financial Analysis: Tools and Technique (McGraw Hill Companies, New York, 2001)

4. M. Striteska, L. Jelinkova, Procedia - Social and Behavioral Sciences 210, 66-76 (2015)

5. M.E. Porter, V.E. Millar, How information gives you competitive advantage (Harvard Business Review 1985)

6. R.S. Kaplan, D.P. Norton, The Strategy Focused Organization: How Balanced Scorecard Companies Thrive in the New Business Environment (Harvard Business School Press, Massachusetts, 2001)

7. R.S. Kaplan, D.P. Norton, The Balanced Scorecard Translating Strategy Into Action (Harvard Business School Press, Massachusetts, 1996) 
8. M. Kennerley, A. Neely, International Journal of Operation and Production Management 20, 754-771 (2000)

9. D.P. Keegan, R.G. Eiler, C.R. Jones, Management Accounting Research 70, (1989)

10. L. Fitzgerald, T.J. Brignall, R. Johnston, R. Silvestro, Management Accounting Research 2, 227-248 (1991)

11. M. Kennerley, A. Neely, International Journal of Operations \& Production Management 22, 1222 1245 (2002)

12. R.S. Kaplan, D.P. Norton, Strategy Maps (Harvard Business School Press Boston, Massachusetts, 2004)
13. S.H. Choi, B.S. Ahn, International Journal of Expert Systems with Applications 38, 7081 - 7087 (2011)

14. A.J. Rohm, V. Swaminathan, Journal of Business Research 57, 748-758 (2004)

15. W. Edwards, F.H. Barron, Organizational Behavior and Human Decision Processes 60, 306 - 325 (1994)

16. F.H. Barron, B.E. Barrett, Internasional Journal Of Acta Psychologica 93, 23-26 (1996)

17. B.S. Ahn, European Journal of Operational Research 212, 552-559 (2011) 